\title{
Kommende kurser
}

- 13. august 2012: Basic FATE, Skejby Sygehus.

- 14. august 2012: Basic ultrasound guided peripheral nerve blocks, Skejby Sygehus.

- 26. september 2012: "Kom godt i gang" kursus i kontrastultralyd, Aarhus Universitetshospital.

- 28. september 2012: 26. Introkursus i akut abdominal ultralydskanning inkl. FAST og E-FAST. Rigshospitalet Overtegnet - muligt at komme på venteliste.
- 29.-31. oktober: 51. Basiskursus i ultralyd, Herlev Hospital.

- 5. november 2012: Basic FATE, Skejby Sygehus.

- 6. november 2012: Basic ultrasound guided peripheral nerve blocks, Skejby Sygehus.

- 26. november 2012: Basic FATE, Skejby Sygehus

- Yderligere oplysninger om kurser, inklusive programmer, kan ses på www. duds.dk 